\title{
Synoptic pattern of deep trough led to strong winds of Zab basin in Iran ${ }^{1}$
}

\author{
Emam Ali. Asheri ${ }^{1}$, Nader. Parvin ${ }^{2, *}$ \\ ${ }^{1}$ Assistant Professor, Department of geography, Payame Noor University, PO BOX 19395-3697 \\ Tehran, IRAN \\ ${ }^{2}$ Assistant Professor, Department of Geography, Payame Noor University, PO BOX 19395-3697 \\ Tehran, IRAN
}

Corresponding Author_n.parvin@kpnu.ac.ir

Keyword: Synoptic pattern, trough, strong winds, Zab Basin

\begin{abstract}
One of the most important natural disasters are storms that each year, causing financial losses and Johnny are Frequency. Sometimes damage to the extent that the economic system, social disrupts a country. The aim of this study is to analyze the synoptic conditions of severe storms is Zab basin. In this study, given the scale of temporal and spatial distribution, wind speed and comprehensiveness of the three threshold size and calculate the 90th percentile wind speed, Forty days pervasive and severe storms were selected. Sea level pressure data and the elevation data of 500hp level from the database NCEP/NCAR were extracted. Matrix was formed that storm was on the rows and elevation data middle levels of the atmosphere, was on the columns. Then, principal components that explain the variation in height level pressure hp500 were identified. To identify synoptic patterns, cluster analysis integration "ward's" was performed on these components.

The results showed that five synoptic pattern of atmospheric middle level, in the form of three major causes of severe storms in the Zab River Basin: Cut off low pattern, Shallow trough pattern of long wave and deep trough pattern of short wave. The most frequent traffic synoptic pattern of a synoptic pattern of middle levels and $60 \%$ of the patterns assigned to itself, causing severe storms in the Zab River Basin. Irregularities in the movement and position of the polar vortex caused the jet stream and storm paths meridian winds greater control and troughs are driven towards the low latitudes deeper. Because of the special arrangement of relatively strong and contrasting surface synoptic, the pressure gradient and energy exchange at its maximum reached compression Isobaric lines and as a result, Strong winds in the catchment area level has been created.
\end{abstract}

\section{INTRODUCTION}

One of the main ways to prevent and deal with severe storms detect patterns of atmospheric circulation is generating strong winds and storm warning systems. Certainly, vacuum is necessary to study hurricanes and more important, if the economy, the size and scope of the consequences of severe storms (direct and indirect) to be evaluated .The main part of a severe storm warning system, is the model prediction and forecasting in time, and with the risk of potential losses sure, will decrease. Classification of types of atmospheric circulation patterns or extreme changes in climate weather useful tool and are the most important method of identification. Whereas, almost all climate disasters directly or indirectly associated with high levels of atmospheric circulation patterns. Whereas, almost all climate disasters directly or indirectly associated with high levels of atmospheric circulation patterns, the synoptic weather pattern weather deep trough led to strong winds of Zab basin related to severe storms will be inevitable Zab catchment area. Therefore, the main objective of this research is to identify and categorize the atmospheric circulation patterns associated with the occurrence of severe storms Zab basin using advanced statistical methods and their synoptic interpretation. It is hoped that by providing practical, small steps can be taken to reduce damage caused by storms catchment area. Researchers' studies on Violent storms have done a number of synoptic method. Including, notably, the following important things:

Abatzoglou et al (2013: 704) were detected to detect the winds of Santa Ana, California, dynamic and thermodynamic factors at scale synoptic through, using reconstructed data mean sea 
level pressure gradients and advection of lower troposphere temperatures, strong winds and coastal incendiary the threshold and two parameter model.

The results showed that, in the event of strong winds, the slope of the average pressure at sea level was much lower in the troposphere to the northeast. They also found that the lower troposphere, cold air advection provide an easy and effective tool for the detection of strong winds in the synoptic scale.

Oltmanns et al (2014: 992) located in East Greenland shelf Fjord cyclone was due to the presence of strong cyclones and severe cold weather and dry wind the ice sheet plateau. They are very effective role leeward slopes and beaches in the fjord valley wind speeds increase due to strong pressure gradient found.

Rich research history of the survey and analysis of time and space Winds situation in Iran goes back to the past 20 years. Including the ability to research Jahangir et al. (1384), Alamdary and et al. (1390), Asadi and et al. (1392) and Rezaei Banafsheh. et al (1393) pointed to the potential for wind energy assessment. Other researchers such as Zolphaghari (1383), Kamijani and et al (1391), Halabyan and Porjezy (1393) have investigated the quantitative and qualitative statistical and geographical winds. However, number of studies are few and obvious lack of studies on the identification of large-scale synoptic patterns associated with wind gusts or storms, especially in the interior, however, is worthy of mention: Coral (1372), Hussein (1379), Abedzadeh (1384), Mhrshahy and Nekounam (1388), Zulfikar et al (1390) investigated the climatology of synoptic winds and identify synoptic patterns related to environmental and climate disasters.

Barati and Fleetwood (1386: 72) chose 20 of the 61 significant wave of strong wind in order to design the synoptic patterns strongest winds southern shore of the Caspian Sea. They then check the daily weather maps and directions checkup landing pattern $500 \mathrm{hPa}$ concluded that, during the heyday of concentrated wind speed landing the dominant topics during the heyday of the polar front jet streams blowing in the West Sea and makeup is located between 50-40 degrees during the East. In another study, social and Qanqormeh (1388: 145) concluded that, with the approach of the peripheral circulation and to identify and predict the possibility of producing a variety of weather patterns storm levels higher than $50 \mathrm{~cm}$ in the southern coast of the Caspian Sea, using synoptic data and time data derived from the CDC and level meter stations along the Caspian coast from its inception until 1385, with inflation sea level on the southern shores of the Caspian, weather patterns defined five different scenarios of planetary systems and anticyclone over the Caspian Sea and their adjacent areas. Stemming the flow of this system was that of the 10 geographical regions of the Caspian Sea.

\section{MATERIALS AND METHODS}

Little Zab River Basin is located in the south-west of West Azerbaijan province, including the cities of Piranshahr, Sardasht, Baneh and the three urban centers of approximately 370 thousand people in its place

Overall, in this study severe storms with environmental approach to circulation was investigated. In this study, two data sets are needed: a low level of atmospheric data, including sea level pressure $(\mathrm{slp})$, the wind speed $(\mathrm{m} / \mathrm{s})$ and wind direction and other weather data Zab catchment area of upper level includes: geopotential (hgt) in meters (table 1).

Table 1 Geographic View weather stations Zab catchment area

\begin{tabular}{|l|l|l|c|}
\hline Station & Latitude & Longitude & Altitude (m) \\
\hline Piranshahr & $36^{\circ} 40^{\prime}$ & $45^{\circ} 08^{\prime}$ & 1455 \\
\hline Sardasht & $36^{\circ} 09^{\prime}$ & $45^{\circ} 30^{\prime}$ & 1670 \\
\hline Bane & $36^{\circ} 00^{\prime}$ & $45^{\circ} 54^{\prime}$ & 1600 \\
\hline
\end{tabular}

In view of the scale spatiotemporal distribution, 40 severe storms catchment area were selected. Then, the daily pressure of $500 \mathrm{hPa}$ height on the ground and gusty stations located in the range of 0 to 80 degrees East longitude and latitude 0 to 80 degrees north of the website were taken 
www.esrl.noaa.gov. Above 864 cells will be in the range of distances between each cell in $2.5 * 2.5$ degrees. Then, factor analysis and hierarchical clustering techniques "imported" was used to classify severe storms synoptic patterns of the studied area. In summary, in this study, factor analysis formula (1) can be written as:

$$
Y_{i}=\mu_{i}+\lambda_{i 1} F_{1}+\lambda_{i 2} F_{2}+\ldots+\lambda_{i 6} F_{6}+e_{i} \quad i=1,2, \ldots, 864
$$

In this formula, ${ }^{e_{j k}}$ distance between the observation $\mathrm{j}$ and $\mathrm{k}$ in a set of observations. ${ }^{x_{i j}}$ is value of the variable $i$ in the value of the variable $j$ and $n$ is the number of variables for each member. At the end of each cluster was drawn ink drawings. But in order to better interpret maps, finally, one day in each cluster having the highest correlation with other cluster members was elected as the representative for the synoptic analysis. In total, for the identification and classification of synoptic patterns were following steps:

In the first stage is used according to the study of climatology appropriate data in the form of a combination of an element (pressure) a few places (network crosses NCEP/NCAR) and the time (Stormy days). In the second step the data matrix was prepared taking into account the study on the $\mathrm{S}$ or S-mode. Thus, the matrix of the data set of 40 rows (stormy day) in 864 column or variable (height at $500 \mathrm{hPa}$ ). The third phase was the matrix of correlations between data. Then, the covariance matrix of correlations were calculated.

The fourth stage is calculated based on initial eigenvalues matrix, the number of operating results was selected. In the fifth step, the cluster analysis to identify synoptic patterns $500 \mathrm{hPa}$ producing severe storms, based on six factors were obtained from factor analysis, windy days with minimum Euclidean distance

\section{RESULTS AND DISCUSSION}

\section{Deep East-West traffic pattern Group Europe Greece}

In general, as the synoptic pattern on 26/12/1986 atmospheric middle level implies a short but deep traffic is deployed on top of the central Mediterranean area. Polar vortex has penetrated the low latitudes than normal. So that the line of $500 \mathrm{hPa}$ height less than 5350 meters on the circuit latitude 55 degrees along the meridian $20^{\circ}$ East longitude. In addition, the level height, the subtropical high pressure has settled over lower latitudes and maximum impact on climate has come to the southern coast of Oman. On the other hand, the arrangement is such that waves westerly winds, westerly winds are landing site deep short wave over Greece. This traffic is driven along 40 degrees north latitude and 20 degrees from points east longitude from northern Greece to northwestern Libya. Traffic is the depth of about 25 degrees latitude and altitude difference is 350 meters. Because the distance of $500 \mathrm{hPa}$ height very compact and close together, the speed of westerly winds in the middle layers of the atmosphere to 30 meters per second and has a fairly strong jet stream is created. So that it is drawn along the direction of the south-western axis of the West, Turkey to the south of Algeria(Figure 1). 


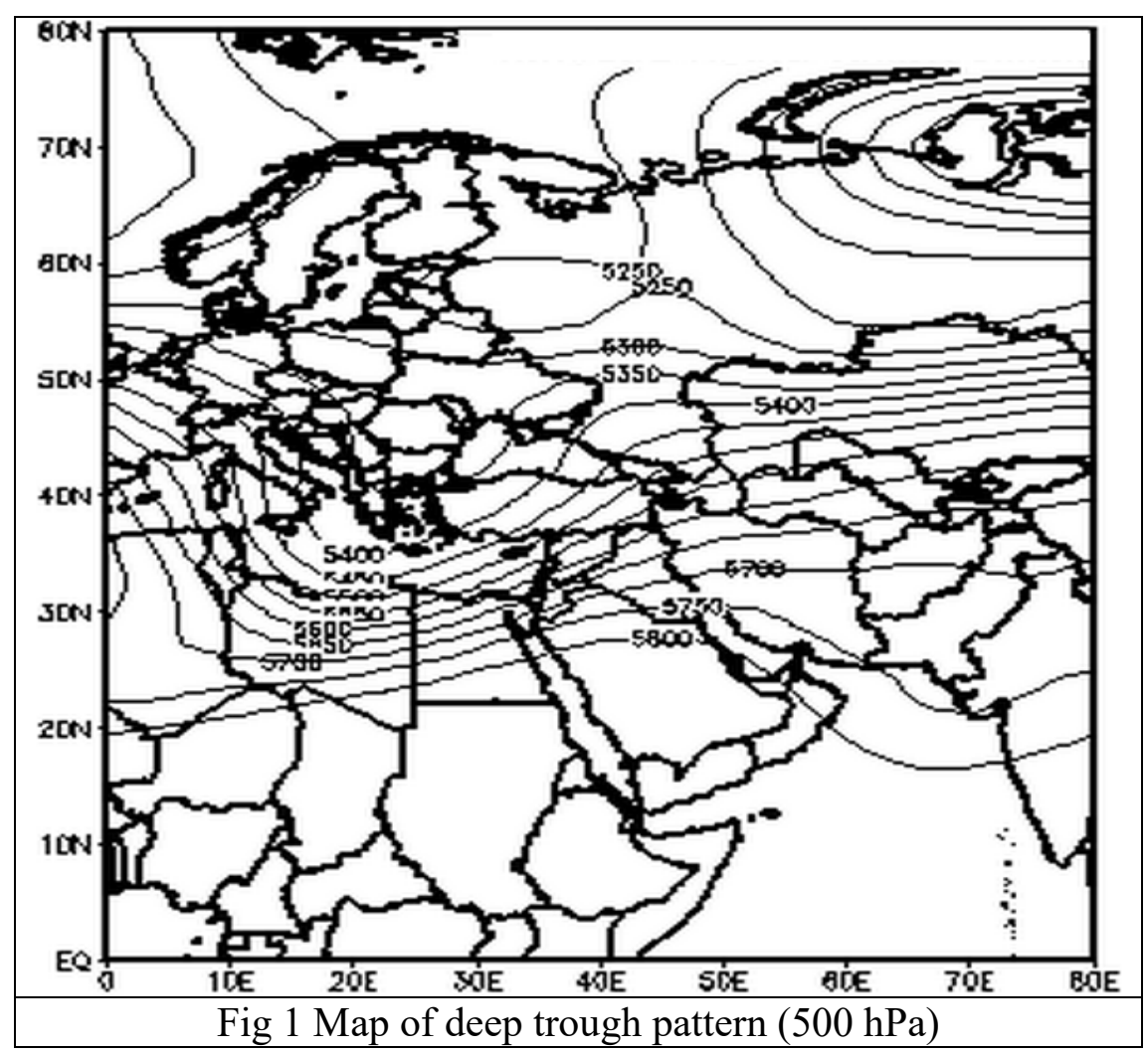

Check-scale distribution when stormy days indicated that strong winds caused by the pattern occurred mainly in March. At this time, the arrangement pattern of westerly winds has tended to meridional wind and synoptic systems in a longer shelf life has been and continues to be unstable. Check the map sprawl sea level pressure indicates that Frabar tab Siberia to the Arabian Peninsula and Central Europe are drawn. Iran has a strong high-pressure system over the central core of the ruling is that the pressure is 1020 mbar. On the other hand, a relatively strong low pressure system is forming curved inner Isobaric 1002 mbar and is located on the Black Sea. How to make a relatively strong position of the two systems and the opposite of the way that Zab basin is located in the high latitudes of the two air masses cool and dry, warm and humid lower latitudes. As the name suggests, are Isobaric lines in the basin are smaller and more compact. Therefore, the pressure gradient, the temperature difference, change the direction of the winds and the energy exchange and eventually reaches its maximum wind speed of 27 meters per second occurred from the West and South West (Figure 2). 


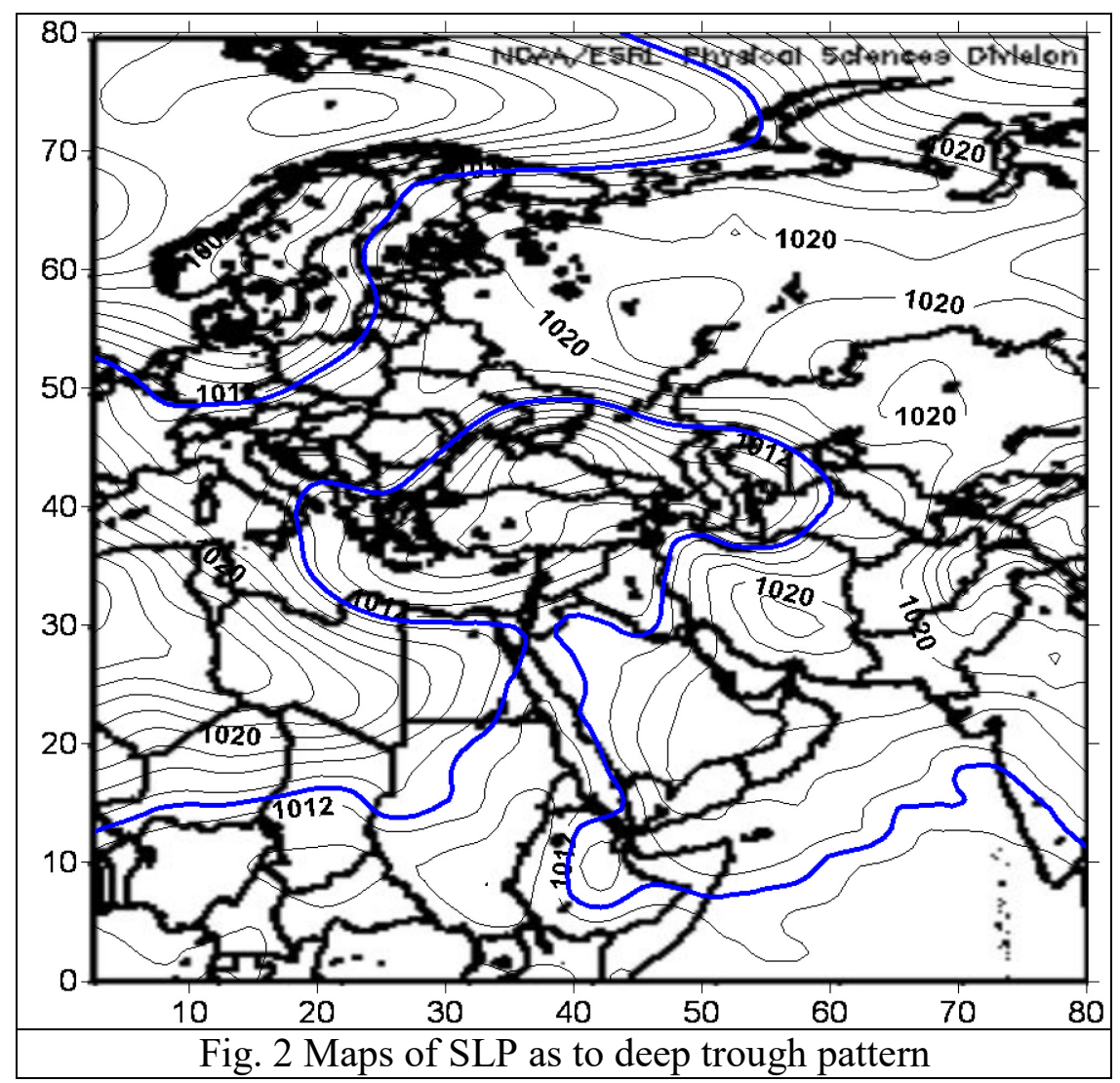

\section{CONCLUSIONS AND RECOMMENDATIONS}

The results of the planning matrix and PCA data on $500 \mathrm{hPa}$ height variance matrix of days with severe storms Zab catchment area showed that the $K M O \geq 0 / 9$ and calculated output value is the determinant of the matrix of correlation coefficients equal to zero Overview table as well as the correlation matrix derived factors also indicate the lack of association between them and complete independence from the other factors (Table 2), so factor analysis was appropriate. The results obtained suggest a possible explanation of the components of the base with 6 components $97.4 \%$ of the atmosphere in terms of pressure elevation changes.

Table 2 Covariance matrix of factors

\begin{tabular}{|c|c|c|c|c|c|c|}
\hline components & First & Second & Third & Fourth & Fifth & Sixth \\
\hline First & 1 & 0 & 0 & 0 & 0 & 0 \\
\hline Second & 0 & 1 & 0 & 0 & 0 & 0 \\
\hline Third & 0 & 0 & 1 & 0 & 0 & 0 \\
\hline Fourth & 0 & 0 & 0 & 1 & 0 & 0 \\
\hline Fifth & 0 & 0 & 0 & 0 & 1 & 0 \\
\hline Sixth & 0 & 0 & 0 & 0 & 0 & 1 \\
\hline
\end{tabular}

The first component explains only $45.2 \%$ of your hp500 level changes, the model was accepted. Violent storms in 14 days with Euclidean distance in five different clusters were separated from each other after performing cluster analysis integration "enter" on a matrix score of 6 main components. The results from the scale distribution of days in each cluster showed that $52 \%$ of days with deep traffic rule synoptic pattern happened in May and November (a total of 12 storms) and $26 \%$ more in December, January and March (two each storm) is assigned.

Synoptic patterns identified during stormy weather conditions prevailing on selected days are named in middle levels. The synoptic pattern of a shallow trough of the southern Mediterranean was alone 50\% in April And distribution of synoptic patterns in both groups also showed that, the deep trough of the most frequent synoptic pattern of the middle levels and $60 \%$ of the patterns, causes violent storms in the Zab River Basin. 


\section{CONCLUSIONS AND RECOMMENDATIONS}

In this study, in order to identify and analyze synoptic storms Zab basin, with three threshold measure wind speed and comprehensiveness of and calculate the 90th percentile wind speed pervasive and severe storms of 40 days from the basin was selected. The occurrence of these storms were observed with the exception of summer all year round. After getting lower and middle levels of the atmosphere and collect elevation data from the US National Oceanic and Atmospheric on covariate matrix atmospheric middle level elevation data, principal component analysis was performed, and $6 \%$ of the components 97.4 the pressure of the atmosphere height variances. To identify synoptic patterns on these components integrate into the cluster analysis was performed. Finally, five synoptic pattern affecting the storms were identified. The result of this study is a useful value (1383) is consistent. As they came in the mid-latitude atmosphere traffic to the East Mediterranean gradient of increasing pressure on the region know.

Overall, the study concluded that, on April the highest rate of $33 \%$ and $52 \%$ of the maximum number of storm days with traffic rule synoptic pattern deep in the May and November happened. On the other hand, accounted for $60 \%$ of total group of deep trough patterns, the most common of synoptic pattern that causes violent storms in the middle levels of the Zab River Basin. The study area is increased and after synoptic pattern of deep trough formed.

Based on the results, in order to prevent or reduce financial damage and even death due to the severe storm that one of the natural threats to the inhabitants of the region, it is suggested that, considering the distribution of time, location and size of the potential damage Gusts and to prevent or reduce the damage, storm early warning system designed to be installed on the Zab River Basin.

1 This project sponsored by PNU Kurdistan province and in particular credit (Grant) has been performed.

\section{References}

[1] Asadi, M. Entezari, A.R. and Akbari, E., (1392), "locating wind farms in the North East of the country using the AHP and GIS" Geographical Studies of Arid, 14: 11-29.

[2] Barati, G.H. and Ashori, F., (1386), "Trahyalgvhay synoptic strongest winds of the southern shore of the Caspian Sea during the years (88-1366)" Geographical Research, 62: 80-67.

[3] Jahangir, Z. Rahimzadeh, F. Kamali, G.A., (1384), "wind energy calculation using the twoparameter Weibull distribution" Geographical Research Quarterly, 76: 170-151.

[4] Hosseini, S.B., (1379), "synoptic study of severe storms in Tehran," Master Thesis, Geography, Faculty of Natural Resources, Tarbiat Modarres University.

[5] Halabian, A. and Hosein Ali Pvrjzy, F., (1393), "Analysis of the frequency of extreme rainfall events associated with the jet stream and the western shores of the Caspian inclusive" Geographical Research, 112: 220-205.

[6] Zolphaghari, M., (1383), "the synoptic pattern winds with speed more than $36 \mathrm{~km}$ per hour in Qom to predict the time that" the Management and Planning Organization of Qom, 326.

[7] Zolfagari, H. Masvmpor Smakosh, J. Shayeghan mehr, S. and Ahmadi, M., (1390), "The Synoptic dust storms in western regions of Iran during the years 88-1384 (Case Study rising tide of July 1388)" Journal of Geography and Program 43: 34-17.

[8] B. Rezaei Banafshah, M. Jahanbakhsh, S. Dinpaghoh, J. and Ismailpor, M., (1393), "the feasibility of using wind power in the province of Ardabil and Zanjan" Geography Research, Volume 46, 3: 261-274.

[9] Abedzadeh, H., (1384), "analyzes dust systems in the West" Supervisor Hassan Zolfaghari, Tarbiat Modarres University, 116. 
[10] Alamdari, P, Nehmatollahi, O. Mirhoseini, S.M. Rajabi, A.A.A., (1390), "The potential of wind energy in this province for the construction of wind power plants" Proceedings of the First International Conference on Emerging Trends in energy conservation Tehran , 30-29 November.

[11] Kamijani, F. Nasrollahi, A. Shaherzad, N. and Nazari, N., (1391), "Analysis of the northern coast of Persian Gulf wind pattern based on systematic winds, the sea breeze and land breeze" Proceedings of the Tenth International Conference on Coasts, Ports and Offshore, 29 November to 1 December 1391, Tehran Olympic Hotel.

[12] Marjani, S.S., (1372), "The synoptic winds over 15 meters per second (storm) in Khorasan" MS Thesis Ecology and Tehran University's Geophysics Institute.

[13] Abatzoglou, J.T., Barbero, R., and Nauslar, J.N., (2013),"Diagnosing Santa Ana Winds in Southern California with Synoptic-Scale Analysis" Wea. Forecasting, 28: 704-710.

[14] Oltmanns, M., Straneo, F., Moore, G.W.K., Mernild, S.H. (2014),"Strong Downslope Wind Events in Ammassalik, Southeast Greenland" Journal of Climate, 27: 977-993. 